\title{
UPAYA MENINGKATKAN KEMAMPUAN BELAJAR SISWA MELALUI PENDEKATAN KETERAMPILAN PROSES
}

\author{
Ii Bidayah \\ SDN Ganeas I kec. Talaga \\ bidayah1408@gmail.com
}

\begin{abstract}
This study originated from the problems felt by researchers that so far learning science in elementary schools (SD) in general still emphasizes the development of cognitive aspects. Students are required to master teaching materials delivered by the teacher without being given the opportunity to develop other aspects. As a result of this learning style, it makes students experience learning difficulties and student learning achievement is still determined by the mastery of the material delivered without regard to other aspects (affective and psychomotor). The research method used is the Classroom Action Research (CAR) method, which is an action to improve and improve the quality of learning. The instrument used was the observation sheet and learning outcomes test. The data analysis technique used is qualitative and quantitative descriptive. Improved teacher performance in designing learning successively increased from cycle I to cycle II, so the teacher's performance in applying the science process skills approach. The increase also has an impact on improving student learning abilities.
\end{abstract}

Keywords: Learning ability, Process Skill Approach

\section{ABSTRAK}

Penelitian ini berawal dari permasalahan yang dirasakan peneliti bahwa selama ini pembelajaran IPA di Sekolah Dasar (SD) pada umumnya masih menekankan pada pengembangan aspek kognitif. Siswa dituntut untuk menguasai bahan ajar yang disampaikan oleh guru tanpa diberi kesempatan untuk mengembangan aspek lainnya. Akibat dari gaya belajar seperti ini membuat siswa mengalami kesulitan dalam belajar dan prestasi belajar siswa masih ditentukan oleh penguasaan materi yang disampaikan tanpa memperhatikan aspek lainnya (afektif dan psikomotor). Metode penelitian yang digunakan adalah metode Penelitian Tindakan Kelas (PTK) dengan desain Kemmis dan Mc'Taggart. Penelitian ini dilaksanakan di SDN Ganeas I Kecamatan Talaga Kabupaten Majalengka dengan subyek penelitian siswa kelas V pada tahun pelajaran 2018/2019. Instrumen yang digunakan adalah lembar observasi dan tes hasil belajar. Teknik analisis data yang digunakan adalah kualitatif dan kuantitatif deskriptif. Peningkatan kinerja guru dalam merancang pembelajaran secara berturut-turut meningkat dari siklus I hingga siklus II, begitu kinerja guru dalam menerapkan pendekatan keterampilan proses sains. Peningkatan tersebut berdampak pula pada peningkatan kemampuan belajar siswa.

Kata Kunci: Kemampuan belajar, Pendekatan Keterampilan Proses

Submitted November 7, 2019 | Revised December 5, 2019 | Accepted December 6, 2019

\section{Pendahuluan}

Pendidikan hakikatnya adalah upaya membantu manusia agar mampu mewujudkan diri sesuai dengan kodrat dan martabat kemanusiaannya, atau mampu melaksanakan berbagai peranan sesuai dengan statusnya berdasarkan nilai-nilai dan norma-norma yang diakuinya. Untuk itu, diperlukan adanya kerjasama antara pendidik dan orang tua sebagai pihak pertama dalam penyelenggaraan pendidikan. Dalam Undang-Undang RI No.20 Tahun 2003 Tentang Sisdiknas, Bab 1 Pasal 1 Ayat 1 menyatakan bahwa pendidikan adalah Usaha sadar dan terencana untuk mewujudkan suasana belajar dan proses pembelajaran agar peserta didik secara aktif mengembangkan potensi dirinya untuk memiliki kekuatan spiritual keagamaan, pengendalian diri, kepribadian, kecerdasan, akhlak mulia, serta keterampilan yang diperlukan dirinya, masyarakat, bangsa dan Negara. Bila ditelaah lebih jauh, pendidikan merupakan proses budaya untuk 
meningkatkan harkat dan martabat manusia. Karena itu, peranan dan tugas pendidik tidak hanya menyampaikan sejumlah ide atau ilmu pengetahuan semata kepada anak didiknya, tetapi mempunyai tanggung jawab moral terhadap Tuhan Yang Maha Esa untuk membimbing anak didiknya dalam mengembangkan potensi yang mereka miliki agar menjadi mandiri, bertanggung jawab terhadap kehidupannya pada masa depan. Surahman (dalam Suherman. 2000: 5 ) mengungkapkan bahwa kekuatan dan mutu pendidikan suatu Negara dapat dinilai dengan faktor guru sebagai salah satu indeks utama. Itulah sebabnya mengapa guru merupakan faktor yang mutlak di dalam pembangunan, makin bersungguh-sungguh suatu pemerintah untuk membangun negaranya, maka menjadi urgen kedudukan guru.

Melihat keterangan di atas, maka dapat di simpulkan bahwa salah satu kunci keberhasilan pengajaran guru, guru harus menguasai metode pengajaran yang baik dan tepat. Di harapkan dengan penerapan metode yang baik dan tepat akan lebih efektif dalam proses belajar mengajar yang di lakukan oleh guru untuk mencapai tujuan pembelajaran yang diharapkan salah satunya yaitu untuk meningkatkan kemampuan belajar siswa, khususnya pembelajaran mata pelajaran Ilmu Pengetahuan Alam (IPA) yang masih dianggap sulit sebagian besar siswa. Begitu pula terjadi pada siswa kelas V SDN Ganeas I Kecamatan Talaga Kabupaten Majalengka.

Berdasarkan pengamatan, faktor penyebab dari ketidakmampuan siswa kelas V SDN Ganeas I Kecamatan Talaga Kabupaten Majalengka pada konsep Gaya Gravitasi adalah guru belum menemukan strategi yang tepat dalam pembelajaran, sehingga siswa hanya mendapat materi yang berbentuk hafalan saja yang mengakibatkan rendahnya kualitas pembelajaran. Maka sangatlah penting bagi guru untuk memenuhi tuntutan karakteristik materi, peserta didik dan metodologi pembelajaran dalam proses pembelajaran yang modern, lebih kreatif, inovatif dan konstruktif dalam merekonstruksi wawasan pengetahuan siswa. Sehubungan dengan hal tersebut, perlu suatu inovasi yang dapat mengatasi masalah di atas antara lain melalui pendekatan keterampilan proses.

Keterampilan proses adalah keterampilan yang melibatkan keterampilan-keterampilan kognitif atau intelektual, manual dan sosial. Keterampilan kognitif terlibat karena dengan melakukan keterampilan proses siswa menggunakan pikirannya (Rustaman, 2003),. Keterampilan manual jelas terlibat dalam keterampilan proses karena mereka melibatkan penggunaan alat dan bahan, pengukuran, penyusunan atau perakitan alat. Keterampilan sosial juga terlibat dalam keterampilan proses karena mereka berinteraksi dengan sesamanya dalam melaksanakan kegiatan belajar-mengajar, misalnya mendiskusikan hasil pengamatan. Keterampilan proses perlu dikembangkan melalui pengalaman-pengalaman langsung sebagai pengalaman belajar. Melalui pengalaman langsung, seseorang dapat labih menghayati proses atau kegiatan yang sedang dilakukan. Menurut Dimyati (2009), kelebihan Keterampilan proses sains (KPS) diantaranya adalah KPS dapat memberikan rangsangan ilmu pengetahuan, sehingga siswa dapat memahami fakta dan konsep ilmu pengetahuan dengan baik, KPS Memberikan kesempatan kepada siswa bekerja dengan ilmu pengetahuan, tidak sekedar menceritakan atau mendengarkan cerita tentang ilmu pengetahuan. Hal ini menyebabkan siswa menjadi lebih aktif, KPS membuat siswa menjadi belajar proses dan produk ilmu pengetahuan sekaligus.

Penggunaan pendekatan keterampilan proses dalam pembelajaran IPA di SD sangat memerlukan pemahaman guru terhadap tahap-tahap perkembangan siswa. Dalam kegiatannya guru dapat menciptakan kondisi belajar yang bervariasi agar siswa dapat terlibat dalam berbagai 
pengalaman. Siswa dapat merencanakan, melaksanakan, dan menilai sendiri hasil kegiatan kelompoknya dengan memberikan tanggapan terhadap kelompok yang lain. Pendekatan proses adalah suatu pendekatan pengajaran yang memberikan kesempatan kepada siswa untuk menghayati proses penemuan atau penyusunan suatu konsep sebagai suatu keterampilan proses. Pendekatan proses dalam pembelajaran dikenal juga sebagai keterampilan proses. Keterampilan proses adalah ketrampilan yang diperoleh dari latihan kemampuan-kemampuan mental, fisik, dan sosial yang mendasar sebagai penggerak kemampuan-kemampuan yang lebih tinggi, kemampuankemampuan mendasar yang telah dikembangkan dan terlatih lama kelamaan akan menjadi suatu keterampilan.

\section{Metode Penelitian}

Metode yang digunakan dalam penelitian ini adalah penelitian tindakan kelas. Penelitian tindakan kelas dilaksanakan secara kolaboratif antara guru dan rekan kerja. Menurut Suharsimi (2006 : 17 ) dalam penelitian kolaborasi, pihak yang melakukan tindakan adalah guru itu sendiri, sedangkan yang diminta melakukan pengamatan terhadap berlangsungnya proses tindakan adalah peneliti, bukan guru yang sedang melakukan tindakan. Kolaborasi juga dapat dilakukan oleh dua orang guru, yang dengan cara bergantian mengamati, ketika sedang mengajar dia adalah seorang guru, ketika sedang mengamati, dia adalah seorang peneliti.

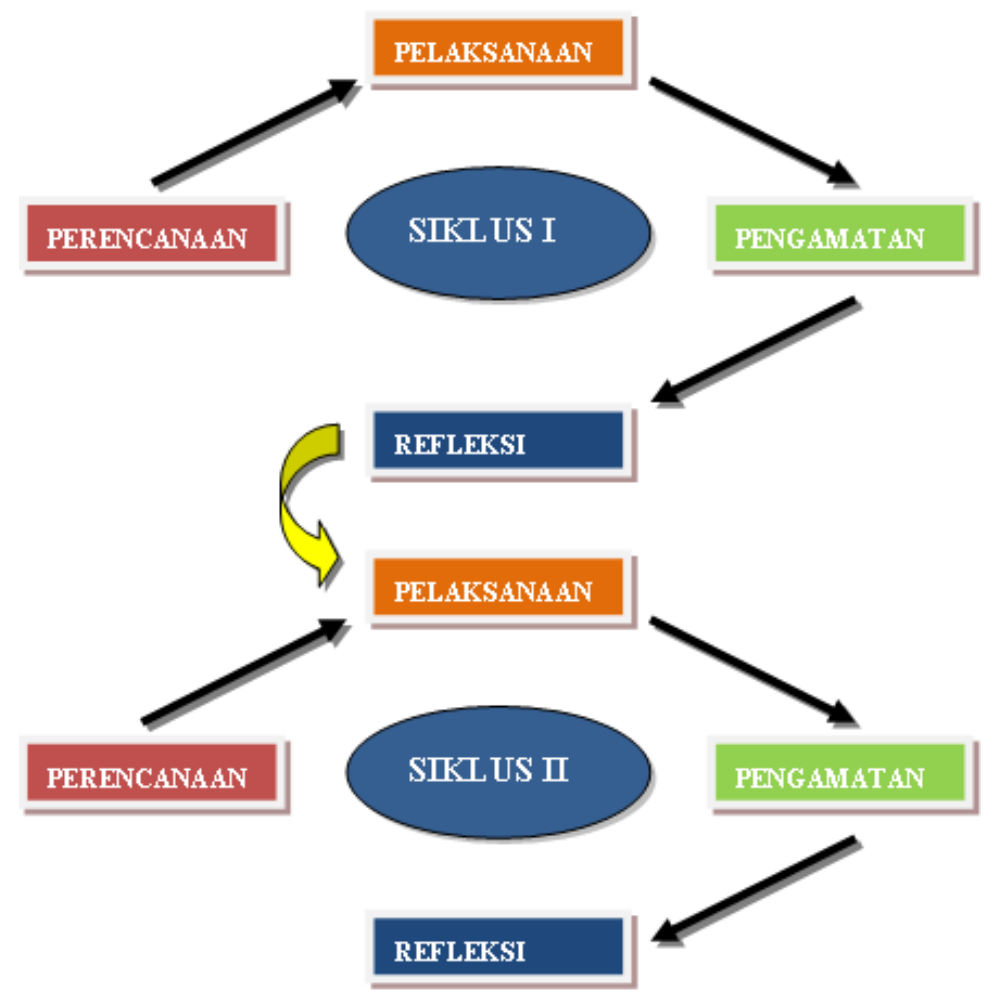

Gambar 1. Desain PTK

Menurut Kunandar (2008:65) pentingnya PTK bagi guru adalah:

1. Membuat guru peka dan tanggap terhadap dinamika pembelajaran di kelas;

2. Meningkatkan kinerja guru, 
3. Guru mampu memperbaiki proses pembelajaran melalui suatu kajian yang dalam terhadap apa yang terjadi di kelas;

4. Dengan melaksanakan PTK berarti guru telah menerapkan pengajaran yang reflektif, artinya guru secara sadar, terencana, dan sistematis melakukan refleksi atau perenungan terhadap kegiatan pembelajaran yang telah dilakukan.

Pada penelitian ini menggunakan media siklus menurut Kemmis (dalam Herawati, 2008: 12). Model siklus menurut Kemmis sebenarnya hampir sama dengan yang lain akan tetapi, proses tindakan dan observasi dijadikan satu. Penelitian tindakan kelas ini didasarkan pada permasalahan yang dihadapi guru dalam kegiatan belajar mengajar. Untuk mengetahui kekurangan selama proses pembelajaran di kelas, peneliti memerlukan bantuan pengamat/observer dalam melakukan penelitian.

Secara umum pelaksanaan penelitian tindakan kelas dapat digolongkan menjadi empat tahapan yaitu :

a. Tahap perencanaan

b. Tahap pelaksanaan

c. Tahap observasi

d. Tahap refleksi.

Penelitian Tindakan Kelas (PTK) dilaksanakan di SDN Ganeas I Kecamatan Talaga Kabupaten Majalengka, dengan subyek penelitian siswa kelas V pada tahun pelajaran 2018/2019. Instrumen yang digunakan dalam penelitian ini terdiri dari perangkat pembelajaran, lembar observasi kegiatan belajar mengajar, Tes formatif. Perangkat pembelajaran yang digunakan berupa Silabus dan RPP, dan Lembar Kegiatan Siswa (LKS). Lembar observasi kegiatan belajar mengajar digunakan untuk mengumpulkan data aktivitas guru dan siswa selama pembelajaran IPA dengan menggunakan keterampilan proses sains. Tes formatif disusun berdasarkan tujuan pembelajaran yang akan dicapai. Tes formatif ini diberikan setiap akhir putaran. Bentuk soal yang diberikan uraian.

\section{Hasil dan Pembahasan}

1. Kemampuan Awal Siswa

Pembelajaran IPA di kelas V SDN Ganeas I Kecamatan Talaga Kabupaten Majalengka sudah sesuai dengan Kurikulum Tingkat Satuan Pendidikan (KTSP) 2006 namun pelaksanaannya belum maksimal, karena proses belajarnya masih menuntut siswa untuk menguasai konsep yang dijelaskan oleh guru dan yang ada dibuku paket (aspek kognitif) sehingga ada sebagian siswa yang kurang memahami terhadap materi yang disampaikan oleh guru.

Pelaksanaan pengajaran IPA dengan menggunakan pendekatan keterampilan proses sudah diterapkan pada kurikulum sebelumnya. Pada Kurikulum Tingkat Satuan Pendidikan (KTSP) 2006 yang disesuaikan dengan kemajuan Ilmu Pengetahuan dan Teknologi (IPTEK) dalam pembelajaran IPA siswa harus dibekali dengan berbagai keterampilan ilmiah agar siswa dapat mengembangkan sikap rasa ingin tahunya dengan melakukan pengamatan dan percobaan sendiri sehingga diperoleh pengetahuan yang baru. Dengan melakukan diskusi antara peneliti dan guru kelas maka diperoleh informasi mengenai permasalahan dalam penggunaan keterampilan 
melakukan percobaan yaitu keterbatasan waktu, alat peraga, serta pengetahuan yang dimiliki guru tentang pendekatan keterampilan proses.

Dalam kegiatan orientasi dan identifikasi masalah dilakukan tes awal untuk mengetahui pengetahuan awal siswa terhadap materi Gaya Gravitasi. Adapun hasil yang diperoleh dari pre tes adalah seperti yang tertera pada tabel di bawah ini.

\begin{tabular}{llc}
\multicolumn{3}{c}{ Tabel 1 Nilai Hasil Pre Tes } \\
\hline No & \multicolumn{1}{c}{ Nama Siswa } & Pre Tes \\
\hline 1 & Alwa Widi Aisya & 80 \\
2 & Andra Raihan & 60 \\
3 & Fajar Maulana & 60 \\
4 & Fajar Ridan & 60 \\
5 & Falma Altaf Fatihah & 80 \\
6 & Frian Akbar Nurfaisal & 50 \\
7 & Hasbi Andi Nurrahman & 80 \\
8 & Kalvin Noerdi Silvana & 50 \\
9 & Regis Trisutrisno & 50 \\
10 & Rino Agung Permana & 50 \\
11 & Sinta Regita Cahyani & 80 \\
12 & Yogi Poniawan & 50 \\
13 & Ega Putri Riyanti & 70 \\
14 & Refi Alvian Nurkamal & 80 \\
15 & Yusuf Rizki Mubarok & 50 \\
16 & Elin Merlina & 60 \\
17 & Istiqomah & 60 \\
18 & Arman Fauzi & 50 \\
& Jumlah & $\mathbf{1 1 2 0}$ \\
& Rata-rata & $\mathbf{6 2 , 2}$ \\
\hline
\end{tabular}

Berdasarkan hasil evaluasi sebelum melakukan pembelajaran yang menggunakan pendekatan keterampilan proses, diketahui bahwa nilai rata-rata pretes siswa yang dilaksanakan sebelum tindakan adalah 62,2 dengan nilai terendah 50, dan nilai tertinggi 80. Sehingga jika dibanding dengan nilai Kriteria Ketuntasan Minimum 63,3 maka ada 11 orang siswa yang nilainya dibawah KKM dan masih berada dibawah target.

2. Siklus I

Hasil pembelajaran merupakan data hasil keberhasilan siswa dalam mencapai tujuan pembelajaran. Nilai-nilai yang diperoleh siswa pada siklus I adalah sebagai berikut :

Tabel 2 Nilai Hasil Belajar Siswa pada Siklus I

\begin{tabular}{llc}
\hline No & \multicolumn{1}{c}{ Nama Siswa } & Siklus I \\
\hline 1 & Alwa Widi Aisya & 80 \\
2 & Andra Raihan & 70 \\
3 & Fajar Maulana & 60 \\
4 & Fajar Ridan & 70 \\
5 & Falma Altaf Fatihah & 80 \\
\hline
\end{tabular}




\begin{tabular}{llc}
\hline 6 & Frian Akbar Nurfaisal & 60 \\
7 & Hasbi Andi Nurrahman & 70 \\
8 & Kalvin Noerdi Silvana & 50 \\
9 & Regis Trisutrisno & 60 \\
10 & Rino Agung Permana & 60 \\
11 & Sinta Regita Cahyani & 80 \\
12 & Yogi Poniawan & 60 \\
13 & Ega Putri Riyanti & 70 \\
14 & Refi Alvian Nurkamal & 80 \\
15 & Yusuf Rizki Mubarok & 60 \\
16 & Elin Merlina & 70 \\
17 & Istiqomah & 60 \\
18 & Arman Fauzi & 60 \\
& $\quad$ Jumlah & $\mathbf{1 2 0 0}$ \\
& $\quad$ Rata-rata & $\mathbf{6 6 , 7}$ \\
\hline
\end{tabular}

Berdasarkan pengamatan observer diperoleh data bahwa nilai rata-rata siswa pada siklus I adalah 66,7. Hal ini menunjukkan bahwa nilai rata-rata siswa sudah berada diatas target namun ada 9 orang siswa yang nilai hasil belajarnya berada dibawah 63,3.

3. Siklus II

Setelah dilaksanakan evaluasi hasil belajar siswa, maka diperoleh nilai sebagai berikut :

Tabel 3 Nilai Hasil Belajar Siswa pada Siklus II

\begin{tabular}{llc}
\hline No & \multicolumn{1}{c}{ Nama Siswa } & Siklus I \\
\hline 1 & Alwa Widi Aisya & 70 \\
2 & Andra Raihan & 90 \\
3 & Fajar Maulana & 80 \\
4 & Fajar Ridan & - \\
5 & Falma Altaf Fatihah & 80 \\
6 & Frian Akbar Nurfaisal & 90 \\
7 & Hasbi Andi Nurrahman & - \\
8 & Kalvin Noerdi Silvana & - \\
9 & Regis Trisutrisno & 80 \\
10 & Rino Agung Permana & 60 \\
11 & Sinta Regita Cahyani & 70 \\
12 & Yogi Poniawan & 80 \\
13 & Ega Putri Riyanti & 80 \\
14 & Refi Alvian Nurkamal & 70 \\
15 & Yusuf Rizki Mubarok & - \\
16 & Elin Merlina & 70 \\
17 & Istiqomah & 80 \\
18 & Arman Fauzi & 80 \\
& & Jumlah
\end{tabular}


Hasil pengamatan observer tentang nilai rata-rata siswa yang didasarkan pada hasil evaluasi belajar siswa pada siklus II diperoleh data sebesar 77,7. ini menunjukkan ada peningkatan nilai rata-rata siswa meskipun tidak signifikan yaitu sebesar 4,7 dari siklus I dan nilai rata-rata 73,0. Dengan nilai tersebut maka rata-rata siswa pada siklus II sudah mencapai target dan pemahaman siswa meningkat.

Hasil pengamatan peneliti dan observer pada siklus I siswa masih ragu-ragu dan merasa takut salah dalam melakukan percobaan. Dalam pengelolaan kelas masih kurang efektif karena ada sebagian siswa yang asyik dengan kegiatan sendiri, main-main dengan alat dan bahan serta bercanda-canda pada saat guru menjelaskan langkah-langkah percobaan.

Namun pada siklus II dalam mengkondisikan siswa sudah cukup baik. Siswa tidak ragu-ragu dan tidak takut salah dalam melakukan percobaan. Berdasarkan hasil penelitian yang dilakukan, ternyata penggunaan keterampilan melakukan percobaan dapat menarik perhatian siswa untuk aktif dalam belajar. Dengan mengembangkan keterampilan eksperimen dalam percobaan dapat melatih siswa untuk mencari dan menemukan sendiri berbagai jawaban atas persoalan-persoalan yang dihadapinya dan siswa juga dapat menemukan bukti kebenaran dari teori yang sedang dipelajarinya serta dapat melatih siswa untuk berpikir ilmiah.

Tabel 4 Rekapitulasi Hasil Tes Siswa dalam Dua Siklus

\begin{tabular}{llccc}
\hline No & \multicolumn{1}{c}{ Nama Siswa } & Pre tes & Siklus I & Siklus II \\
\hline 1 & Alwa Widi Aisya & 50 & 40 & 70 \\
2 & Andra Raihan & 70 & 80 & 90 \\
3 & Fajar Maulana & 80 & 80 & 80 \\
4 & Fajar Ridan & 60 & 90 & - \\
5 & Falma Altaf Fatihah & 80 & 80 & 80 \\
6 & Frian Akbar Nurfaisal & 50 & 60 & 90 \\
7 & Hasbi Andi Nurrahman & 80 & 70 & - \\
8 & Kalvin Noerdi Silvana & 60 & 60 & - \\
9 & Regis Trisutrisno & 50 & 60 & 80 \\
10 & Rino Agung Permana & 50 & 50 & 60 \\
11 & Sinta Regita Cahyani & 70 & 80 & 70 \\
12 & Yogi Poniawan & 50 & 80 & 80 \\
13 & Ega Putri Riyanti & 70 & 70 & 80 \\
14 & Refi Alvian Nurkamal & 40 & 60 & 70 \\
15 & Yusuf Rizki Mubarok & 80 & 70 & - \\
16 & Elin Merlina & 80 & 90 & 70 \\
17 & Istiqomah & 50 & 90 & 80 \\
18 & Arman Fauzi & - & 80 & 80 \\
& & $\mathbf{1 8 4 0}$ & $\mathbf{2 1 9 0}$ & $\mathbf{1 7 1 0}$ \\
& & $\mathbf{6 3 , 4}$ & $\mathbf{7 3 , 0}$ & $\mathbf{7 7 , 7}$ \\
\hline
\end{tabular}

\section{Kesimpulan}

Hasil penelitian tentang pembelajaran IPA yang menggunakan pendekatan keterampilan proses pada konsep Gaya Gravitasi di kelas V SDN Ganeas I Desa Talagakulon Kecamatan 
Talaga Kabupaten Majalengka dapat disimpulkan : Dari hasil penelitian yang dilakukan penulis diperoleh data bahwa hasil belajar siswa pada mata pelajaran IPA dengan menggunakan pendekatan keterampilan proses terutama melakukan percobaan dapat mencapai target Kriteria Ketuntasan Minimun (KKM) yaitu 67,3. Nilai rata-rata yang diperoleh siswa pada siklus I 66,7 sedangkan pada siklus II 76.

\section{Daftar Pustaka}

Ahmadi Abu, Drs dan Drs, Widodo Supriyono. (2003). Psikologi Belajar. Solo: Rineka Cipta

Arikunto, Suharsimi, dkk (2006). Penelitian Tindakan Kelas. Jakarta : Bumi Aksara

Coony Semiawan, dkk. (1986). Pendekatan Keterampilan Proses: Bagaimana Mengaktifkan Siswa. Jakarta: PT. Gramedia

Dimyati dan Mudjiono. (2009). Belajar dan Pembelajaran. Jakarta: Rineka Cipta

Haryono (2004). Sains untuk SD kelas V. Jakarta: Erlangga

Kardiawarman. (1997). Ensiklopedi Sains dan Kebidupan. CV. Tariti Samudra Berlian. Jakarta

Kunandar (2009). Langkah Mudah Penelitian Tindakan Kelas Sebagai Pengembangan Profesi Guru. Jakarta: Rajawali Pers

Marthen Kanginan. (1989). Buku Pelajaran IP A Fisika SMA. Erlangga. Jakarta

Mulyana, E.H. (2003). Pembelajaran IPA di sekolah dasar. Tasikmalaya: Buku Wajib Perkuliahan IPA PGSD UPI Kampus Tasikmalaya. Tidak di Publikasikan.

Mulyana, E.H. (2006). Kurikulum 2006" Peraturan Mentri Pendidikan Republik Indonesia Nomor 22 Tentang Standar Isi untuk Satuan Pendidikan Dasar dan Menengah". Depdiknas Republik Indonesia.

Ratna Wilis Dahar (1996). Teori-Teori Belajar, Erlangga, Jakarta.

Rustaman, N.Y., dkk. (2003). Strategi Belajar Mengajar Biologi. Bandung: Jurusan Pendidikan Biologi FPMIPA UPI

Sugiono (2007). Metode Penelitian Pendidikan: Pendekatan Kuantitatif, Kualitatif, dan R\&D. Bandung: Alfabeta.

Usman dan Setiawati L. (1993). Upaya Optimalisasi Kegiatan Belajar Mengajar. Rosda Karya. Bandung 